\title{
Risk factors, prognostic factors, and nomograms for bone metastasis in patients with newly diagnosed infiltrating duct carcinoma of the breast: a population- based study
}

Zhangheng Huang ${ }^{1+}$, Chuan $\mathrm{Hu}^{1,2+}$, Kewen $\mathrm{Liu}^{1}$, Luolin Yuan ${ }^{1}$, Yinglun $\mathrm{Li}^{1}$, Chengliang Zhao ${ }^{1 *}$ and Chanchan $\mathrm{Hu}^{3^{*}}$

\begin{abstract}
Background: Breast cancer is the most common malignancy in women, and it is also the leading cause of death in female patients; the most common pathological type of BC is infiltrating duct carcinoma (IDC). Some nomograms have been developed to predict bone metastasis (BM) in patients with breast cancer. However, there are no studies on diagnostic and prognostic nomograms for BM in newly diagnosed IDC patients.

Methods: IDC patients with newly diagnosed BM from 2010 to 2016 in the Surveillance, Epidemiology and End Results (SEER) database were reviewed. Multivariate logistic regression analysis was used to identify risk factors for BM in patients with IDC. Univariate and multivariate Cox proportional hazards regression analysis were used to explore the prognostic factors of BM in patients with IDC. We then constructed nomograms to predict the risk and prognosis of BM for patients with IDC. The results were validated using bootstrap resampling and retrospective research on 113 IDC patients with BM from 2015 to 2018 at the Affiliated Hospital of Chengde Medical University.

Results: This study included 141,959 patients diagnosed with IDC in the SEER database, of whom 2383 cases were IDC patients with BM. The risk factors for BM in patients with IDC included sex, primary site, grade, T stage, N stage, liver metastasis, race, brain metastasis, breast cancer subtype, lung metastasis, insurance status, and marital status. The independent prognostic factors were brain metastases, race, grade, surgery, chemotherapy, age, liver metastases, breast cancer subtype, insurance status, and marital status. Through calibration, receiver operating characteristic curve and decision curve analyses, we found that the nomogram for predicting the prognosis of IDC patients with BM displayed great performance both internally and externally.

(Continued on next page)
\end{abstract}

*Correspondence: 38221965@qq.com; 2053279127@qq.com

†Zhangheng Huang and Chuan Hu contributed equally to this work.

${ }^{1}$ Department of Spine Surgery, Affiliated Hospital of Chengde Medical

University, No.36 Nanyingzi St, Shuangqiao District, Chengde, Hebei Province,

China

${ }^{3}$ Department of Oncology, Affiliated Hospital of Chengde Medical University,

No.36 Nanyingzi St, Shuangqiao District, Chengde, Hebei Province, China

Full list of author information is available at the end of the article

(c) The Author(s). 2020 Open Access This article is licensed under a Creative Commons Attribution 4.0 International License, which permits use, sharing, adaptation, distribution and reproduction in any medium or format, as long as you give appropriate credit to the original author(s) and the source, provide a link to the Creative Commons licence, and indicate if changes were made. The images or other third party material in this article are included in the article's Creative Commons licence, unless indicated otherwise in a credit line to the material. If material is not included in the article's Creative Commons licence and your intended use is not permitted by statutory regulation or exceeds the permitted use, you will need to obtain permission directly from the copyright holder. To view a copy of this licence, visit http://creativecommons.org/licenses/by/4.0/ The Creative Commons Public Domain Dedication waiver (http://creativecommons.org/publicdomain/zero/1.0/) applies to the data made available in this article, unless otherwise stated in a credit line to the data. 
(Continued from previous page)

Conclusion: These nomograms are expected to be a precise and personalized tool for predicting the risk and prognosis for BM in patients with IDC. This will help clinicians develop more rational and effective treatment strategies.

Keywords: Breast cancer, Infiltrating duct carcinoma, Bone metastasis, Predictor, Prognosis, Nomogram

\section{Background}

Breast cancer $(\mathrm{BC})$ is the most common malignancy and the leading cause of death among all female cancer patients $[1,2]$. Globally, there were approximately 2.1 million newly diagnosed female BC cases in 2018 [3]. Recently, with the advancement of early diagnosis and comprehensive treatment, the mortality rate of $\mathrm{BC}$ has gradually decreased, and distant metastasis has become the main cause of death for these patients $[4,5]$. It has been reported that the incidence of metastases in $\mathrm{BC}$ patients ranges from 20 to $30 \%$ [6]. More importantly, bone metastasis (BM) accounts for $50 \%$ of all distant metastases in these patient [7]. At present, most $B C$ patients with $\mathrm{BM}$ receive palliative treatment [8]. Although some patients choose surgery, it is not suitable for patients with multiple metastases or a poor overall health [9]. Some studies have shown that the median survival for patients with breast cancer and BM is only 2436 months [10].

The TNM staging system is the most common tool used to predict the prognosis of cancer patients by assessing tumor size and location $(\mathrm{T})$, distant metastasis $(\mathrm{M})$, and regional lymph node metastasis $(\mathrm{N})$ [11]. However, the TNM staging system does not sufficiently cover cancer biology or predict the outcome for all subtypes of BC [12]. In particular, the TNM staging system fails to quantify the risk for patients with distant metastatic malignancies. Therefore, an increasing number of cancer-related nomograms (statistical tools to estimate the probability of survival or a specific result through a simple graphical representation) have been developed for predicting the prognosis of cancer patients [13]. Nomograms have a number of advantages in predicting the prognosis of some malignant tumors compared to the traditional American Joint Committee for Cancer (AJCC) TNM staging system, making them a good alternative.

It is well established that histological subtypes of breast cancer affect prognosis, and the most common pathological type of $\mathrm{BC}$ is infiltrating duct carcinoma (IDC) [14]. At present, there are no studies that have focused on diagnostic and prognostic nomograms for BM in newly diagnosed IDC patients. Therefore, it is necessary to fully understand the epidemiological characteristics of IDC patients with BM to identify the risk and prognostic factors for BM. Welldeveloped clinical nomograms can be used to predict individual outcomes, which is beneficial to both patients and clinicians [15].

Thus, the aim of this study was to develop a predictive model by analyzing the data of the Surveillance, Epidemiology and End Results (SEER) database to determine the risk and prognosis for BM in patients with IDC.

\section{Methods \\ Patients}

We included patients with newly diagnosed IDC in the SEER database from 2010 to 2016 in our study. Exclusion criteria were as follows: (1) patients with two or more primary malignancies; (2) patients whose pathological type was not IDC; (3) patients missing important clinical pathological information, including laterality, primary tumor site, grade, TNM stage, or estrogen receptor (ER) or progesterone receptor (PR) status, or HER2 status. Finally, 141,959 patients diagnosed with IDC were included in the present study, of whom 2383 patients (1.68\%) had BM, while 139,576 patients $(98.32 \%)$ did not. In addition, we retrospectively collected data for IDC patients with BM from the Affiliated Hospital of Chengde Medical University (AHOCMU) between 2015 and 2018 as an external validation cohort for our research.

\section{Data collection}

The variables were selected to identify the risk factors of BM in IDC patients are as follows: age at diagnosis, sex, race, tumor site, laterality, grade, $\mathrm{T}$ stage, $\mathrm{N}$ stage, liver metastasis, brain metastasis, lung metastasis, breast cancer subtype, ER status, PR status, HER2 status, insurance, and marital status. In our research, we also performed the survival analyses to study the prognostic factors of IDC patients with BM. In addition to the above variables, the treatment information, including surgery, radiotherapy, and chemotherapy, were also included to study the prognostic factors. Moreover, patients with overall survival (OS) less than 1 month were also excluded from the survival analyses. In the survival analysis, 
Table 1 Clinical and pathological features of patients newly diagnosed as infiltrating duct carcinoma of breast

\begin{tabular}{|c|c|c|c|c|c|}
\hline Variables & SEER $(N=141,959)$ & Percent & Variables & SEER $(N=141,959)$ & Percent \\
\hline $\mathrm{Ag}$ & & & Yes & 61,831 & 43.56 \\
\hline $22-54$ & 49,438 & 34.83 & Surgery & & \\
\hline $55-79$ & 81,114 & 57.14 & No & 5465 & 3.85 \\
\hline$\geq 80$ & 11,407 & 8.03 & Yes & 136,494 & 96.15 \\
\hline Race & & & Brain metastasis & & \\
\hline White & 113,888 & 80.23 & No & 141,757 & 99.86 \\
\hline Black & 14,466 & 10.19 & Yes & 202 & 0.14 \\
\hline Other & 13,605 & 9.58 & Liver metastasis & & \\
\hline Sex & & & No & 140,980 & 99.31 \\
\hline Female & 140,883 & 99.24 & Yes & 979 & 0.69 \\
\hline Male & 1076 & 0.76 & Lung metastasis & & \\
\hline Primary Site & & & No & 140,826 & 99.20 \\
\hline Nipple & 479 & 0.34 & Yes & 1133 & 0.80 \\
\hline Central portion of breast & 7319 & 5.16 & Breast subtype & & \\
\hline Upper-inner quadrant of breast & 20,520 & 14.45 & HR-/HER2- & 17,731 & 12.49 \\
\hline Lower-inner quadrant of breast & 9267 & 6.53 & VHR-/HER2+ & 6900 & 4.86 \\
\hline Upper-outer quadrant of breast & 55,426 & 39.04 & $\mathrm{HR}+/ \mathrm{HER} 2-$ & 100,919 & 71.09 \\
\hline Lower-outer quadrant of breast & 12,097 & 8.52 & $\mathrm{HR}+/ \mathrm{HER} 2+$ & 16,409 & 11.56 \\
\hline Axillary tail of breast & 736 & 0.52 & ER status & & \\
\hline Overlapping lesion of breast & 36,115 & 25.44 & Negative & 26,250 & 18.49 \\
\hline Grade & & & Positive & 115,709 & 81.51 \\
\hline I & 31,092 & 21.90 & PR status & & \\
\hline$\|$ & 59,639 & 42.01 & Negative & 40,088 & 28.24 \\
\hline III & 50,920 & 35.87 & Positive & 101,871 & 71.76 \\
\hline IV & 308 & 0.22 & HER2 status & & \\
\hline Laterality & & & Negative & 118,650 & 83.58 \\
\hline Left - origin of primary & 71,742 & 50.54 & Positive & 23,309 & 16.42 \\
\hline Right - origin of primary & 70,217 & 49.46 & Insurance & & \\
\hline T stage & & & Uninsured & 2701 & 1.90 \\
\hline $\mathrm{T} 1$ & 90,286 & 63.60 & Insured & 139,258 & 98.10 \\
\hline $\mathrm{T} 2$ & 42,097 & 29.65 & Marital status & & \\
\hline T3 & 6131 & 4.32 & Unmarried & 53,130 & 37.43 \\
\hline T4 & 3445 & 2.43 & Married & 88,829 & 62.57 \\
\hline
\end{tabular}

NO

N1

N2

N3

Radiotherapy

No

Yes

Chemotherapy

No
99,074

32,876

6570

3439

61,535

80,424

80,128
Table 1 Clinical and pathological features of patients newly diagnosed as infiltrating duct carcinoma of breast (Continued)

69.79

23.16

4.63

2.42

43.35

56.65

the main endpoint of our study was OS, which was defined as the date from diagnosis to death (due to any cause) or the date of the last follow-up. Risk of developing metastasis was defined as the risk of bone metastasis when the patient was first diagnosed with IDC of the breast. Survival prognosis was defined as the OS of the patient who was first diagnosed with IDC of the breast. Our study was approved by the Institutional Research Committee from AHOCMU. 
Table 2 Clinical and pathological features of patients newly diagnosed as infiltrating duct carcinoma with bone metastasis

\begin{tabular}{|c|c|c|c|c|c|c|}
\hline \multirow[t]{3}{*}{ Variables } & \multirow{2}{*}{\multicolumn{2}{|c|}{$\frac{\text { Total cohort }}{N=2383}$}} & \multirow{2}{*}{\multicolumn{2}{|c|}{$\begin{array}{l}\text { Training cohort } \\
N=1671\end{array}$}} & \multirow{2}{*}{\multicolumn{2}{|c|}{$\begin{array}{l}\text { Validation cohort } \\
N=712\end{array}$}} \\
\hline & & & & & & \\
\hline & $\mathrm{n}$ & $\%$ & \multicolumn{2}{|c|}{$\mathrm{n}$} & $n$ & $\%$ \\
\hline \multicolumn{7}{|l|}{ Age } \\
\hline $22-54$ & 851 & 35.71 & 596 & 35.67 & 255 & 35.81 \\
\hline $55-79$ & 1294 & 54.30 & 901 & 53.92 & 393 & 55.20 \\
\hline$\geq 80$ & 238 & 9.99 & 174 & 10.41 & 64 & 8.99 \\
\hline \multicolumn{7}{|l|}{ Race } \\
\hline Black & 317 & 13.30 & 228 & 13.65 & 89 & 12.50 \\
\hline Other & 187 & 7.85 & 123 & 7.36 & 64 & 8.99 \\
\hline White & 1879 & 78.85 & 1320 & 78.99 & 559 & 78.51 \\
\hline \multicolumn{7}{|l|}{ Sex } \\
\hline Female & 2341 & 98.24 & 1638 & 98.03 & 703 & 98.74 \\
\hline Male & 42 & 1.76 & 33 & 1.97 & 9 & 1.26 \\
\hline \multicolumn{7}{|l|}{ Primary Site } \\
\hline Nipple & 13 & 0.55 & 12 & 0.72 & 1 & 0.14 \\
\hline Central portion of breast & 223 & 9.36 & 163 & 9.75 & 60 & 8.43 \\
\hline Upper-inner quadrant of breast & 229 & 9.61 & 170 & 10.17 & 59 & 8.29 \\
\hline Lower-inner quadrant of breast & 156 & 6.55 & 112 & 6.70 & 44 & 6.18 \\
\hline Upper-outer quadrant of breast & 865 & 36.30 & 603 & 36.09 & 262 & 36.80 \\
\hline Lower-outer quadrant of breast & 184 & 7.72 & 133 & 7.96 & 51 & 7.16 \\
\hline Axillary tail of breast & 19 & 0.80 & 10 & 0.60 & 9 & 1.26 \\
\hline Overlapping lesion of breast & 694 & 29.12 & 468 & 28.01 & 226 & 31.74 \\
\hline \multicolumn{7}{|l|}{ Grade } \\
\hline 1 & 156 & 6.55 & 106 & 6.34 & 50 & 7.02 \\
\hline$\|$ & 1104 & 46.33 & 785 & 46.98 & 319 & 44.80 \\
\hline III & 1118 & 46.91 & 777 & 46.50 & 341 & 47.90 \\
\hline IV & 5 & 0.21 & 3 & 0.18 & 2 & 0.28 \\
\hline \multicolumn{7}{|l|}{ Laterality } \\
\hline Left - origin of primary & 1247 & 52.33 & 869 & 52.00 & 378 & 53.09 \\
\hline Right - origin of primary & 1136 & 47.67 & 802 & 48.00 & 334 & 46.91 \\
\hline \multicolumn{7}{|l|}{ T stage } \\
\hline $\mathrm{T} 1$ & 336 & 14.10 & 253 & 15.14 & 83 & 11.66 \\
\hline $\mathrm{T} 2$ & 987 & 41.42 & 670 & 40.10 & 317 & 44.52 \\
\hline T3 & 405 & 16.99 & 291 & 17.41 & 114 & 16.01 \\
\hline $\mathrm{T} 4$ & 655 & 27.49 & 457 & 27.35 & 198 & 27.81 \\
\hline \multicolumn{7}{|l|}{ N stage } \\
\hline NO & 557 & 23.37 & 380 & 22.74 & 177 & 24.86 \\
\hline N1 & 1160 & 48.68 & 820 & 49.07 & 340 & 47.75 \\
\hline $\mathrm{N} 2$ & 321 & 13.47 & 225 & 13.47 & 96 & 13.48 \\
\hline N3 & 345 & 14.48 & 246 & 14.72 & 99 & 13.91 \\
\hline \multicolumn{7}{|l|}{ Radiotherapy } \\
\hline No & 1782 & 74.78 & 1239 & 74.15 & 543 & 76.26 \\
\hline Yes & 601 & 25.22 & 432 & 25.85 & 169 & 23.74 \\
\hline
\end{tabular}

Chemotherapy 
Table 2 Clinical and pathological features of patients newly diagnosed as infiltrating duct carcinoma with bone metastasis (Continued)

\begin{tabular}{|c|c|c|c|c|c|c|}
\hline \multirow[t]{3}{*}{ Variables } & \multirow{2}{*}{\multicolumn{2}{|c|}{$\frac{\text { Total cohort }}{N=2383}$}} & \multirow{2}{*}{\multicolumn{2}{|c|}{$\begin{array}{l}\text { Training cohort } \\
N=1671\end{array}$}} & \multirow{2}{*}{\multicolumn{2}{|c|}{$\begin{array}{l}\text { Validation cohort } \\
N=712\end{array}$}} \\
\hline & & & & & & \\
\hline & $\bar{n}$ & $\%$ & $\bar{n}$ & $\%$ & $\bar{n}$ & $\%$ \\
\hline No & 976 & 40.96 & 688 & 41.17 & 288 & 40.45 \\
\hline Yes & 1407 & 59.04 & 983 & 58.83 & 424 & 59.55 \\
\hline \multicolumn{7}{|l|}{ Surgery } \\
\hline No & 1465 & 61.48 & 1018 & 60.92 & 447 & 62.78 \\
\hline Yes & 918 & 38.52 & 653 & 39.08 & 265 & 37.22 \\
\hline \multicolumn{7}{|l|}{ Brain metastasis } \\
\hline No & 2260 & 94.84 & 1582 & 94.67 & 678 & 95.22 \\
\hline Yes & 123 & 5.16 & 89 & 5.33 & 34 & 4.78 \\
\hline \multicolumn{7}{|l|}{ Liver metastasis } \\
\hline No & 1881 & 78.93 & 1338 & 80.07 & 543 & 76.26 \\
\hline Yes & 502 & 21.07 & 333 & 19.93 & 169 & 23.74 \\
\hline \multicolumn{7}{|l|}{ Lung metastasis } \\
\hline No & 1811 & 76.00 & 1258 & 75.28 & 553 & 77.67 \\
\hline Yes & 572 & 24.00 & 413 & 24.72 & 159 & 22.33 \\
\hline \multicolumn{7}{|l|}{ Breast subtype } \\
\hline HR-/HER2- & 238 & 9.99 & 168 & 10.05 & 70 & 9.83 \\
\hline HR-/HER2+ & 167 & 7.01 & 116 & 6.94 & 51 & 7.16 \\
\hline HR+/HER2- & 1525 & 63.99 & 1091 & 65.29 & 434 & 60.96 \\
\hline $\mathrm{HR}+/ \mathrm{HER} 2+$ & 453 & 19.01 & 296 & 17.72 & 157 & 22.05 \\
\hline \multicolumn{7}{|l|}{ HER2 status } \\
\hline Negative & 1763 & 73.98 & 1259 & 75.34 & 504 & 70.79 \\
\hline Positive & 620 & 26.02 & 412 & 24.66 & 208 & 29.21 \\
\hline \multicolumn{7}{|l|}{ Insurance } \\
\hline Uninsured & 126 & 5.29 & 90 & 5.39 & 36 & 5.06 \\
\hline Insured & 2257 & 94.71 & 1581 & 94.61 & 676 & 94.94 \\
\hline \multicolumn{7}{|l|}{ Marital status } \\
\hline Unmarried & 1101 & 46.20 & 760 & 45.48 & 341 & 47.89 \\
\hline Married & 1282 & 53.80 & 911 & 54.52 & 371 & 52.11 \\
\hline
\end{tabular}

\section{Development of a diagnostic nomogram}

All statistical analyses in our research were performed in $\mathrm{R}$ software (version 3.6.1). To identify the risk factors of BM in IDC patients, univariate analysis was performed. Comparisons of continuous data were performed by independent $t$-tests, while the chi-square test or the Fisher exact probability method were used for categorical data. Variables with a $P$ value < 0.05 in the univariate analysis were included in the multivariate logistic analysis to identify the risk factors for BM in IDC patients. Based on independent risk factors, the rms package was used to build a nomogram and calculate the individual risk score.
Meanwhile, the receiver operating characteristic (ROC) curve was plotted, and the area under the curve (AUC) was used to show the discrimination of the nomogram. Moreover, a calibration curve and decision curve analyses (DCA) were performed to evaluate the nomogram [16].

\section{Development of a prognostic nomogram}

To identify the prognostic factors of IDC patients with BM, 2383 patients were included to perform survival analyses. All BM patients were randomly divided into training $(n=1671)$ and validation $(n=712)$ cohorts with a ratio of $7: 3$. The classification process was completely 
Table 3 Univariate analysis of risk factor of bone metastasis in infiltrating duct carcinoma patients

\begin{tabular}{|c|c|c|c|c|}
\hline Variable & Without bone metastasis number ( $n$ ) & With bone metastasis number $(n)$ & Chi-square & $P$-value \\
\hline \multicolumn{5}{|l|}{ Age } \\
\hline $22-54$ & 48,587 & 851 & 1.447 & 0.148 \\
\hline $55-79$ & 79,820 & 1294 & & \\
\hline$\geq 80$ & 11,169 & 238 & & \\
\hline \multicolumn{5}{|l|}{ Race } \\
\hline Black & 14,149 & 317 & 31.319 & $<0.001$ \\
\hline Other & 13,418 & 187 & & \\
\hline White & 112,009 & 1879 & & \\
\hline \multicolumn{5}{|l|}{ Sex } \\
\hline Female & 138,542 & 2341 & 32.512 & $<0.001$ \\
\hline Male & 1034 & 42 & & \\
\hline \multicolumn{5}{|l|}{ Primary Site } \\
\hline Nipple & 466 & 13 & 148.540 & $<0.001$ \\
\hline Central portion of breast & 7096 & 223 & & \\
\hline Upper-inner quadrant of breast & 20,291 & 229 & & \\
\hline Lower-inner quadrant of breast & 9111 & 156 & & \\
\hline Upper-outer quadrant of breast & 54,561 & 865 & & \\
\hline Lower-outer quadrant of breast & 11,913 & 184 & & \\
\hline Axillary tail of breast & 717 & 19 & & \\
\hline Overlapping lesion of breast & 35,421 & 694 & & \\
\hline \multicolumn{5}{|l|}{ Grade } \\
\hline । & 30,963 & 156 & 354.137 & $<0.001$ \\
\hline$\|$ & 58,535 & 1104 & & \\
\hline III & 49,802 & 1118 & & \\
\hline IV & 303 & 5 & & \\
\hline \multicolumn{5}{|l|}{ Laterality } \\
\hline Left - origin of primary & 70,495 & 1247 & 3.113 & 0.078 \\
\hline Right - origin of primary & 69,081 & 1136 & & \\
\hline \multicolumn{5}{|l|}{ T stage } \\
\hline $\mathrm{T} 1$ & 89,950 & 336 & 8220.550 & $<0.001$ \\
\hline $\mathrm{T} 2$ & 41,110 & 987 & & \\
\hline T3 & 5726 & 405 & & \\
\hline $\mathrm{T} 4$ & 2790 & 655 & & \\
\hline \multicolumn{5}{|l|}{ N stage } \\
\hline No & 98,517 & 557 & 3293.151 & $<0.001$ \\
\hline N1 & 31,716 & 1160 & & \\
\hline N2 & 6249 & 321 & & \\
\hline N3 & 3094 & 345 & & \\
\hline \multicolumn{5}{|l|}{ Brain metastasis } \\
\hline No & 139,497 & 2260 & & $<0.001$ \\
\hline Yes & 79 & 123 & & \\
\hline \multicolumn{5}{|l|}{ Liver metastasis } \\
\hline No & 139,099 & 1881 & $14,692.994$ & $<0.001$ \\
\hline Yes & 477 & 502 & & \\
\hline
\end{tabular}


Table 3 Univariate analysis of risk factor of bone metastasis in infiltrating duct carcinoma patients (Continued)

\begin{tabular}{|c|c|c|c|c|}
\hline Variable & Without bone metastasis number ( $n$ ) & With bone metastasis number $(\mathrm{n})$ & Chi-square & $P$-value \\
\hline \multicolumn{5}{|l|}{ Lung metastasis } \\
\hline No & 139,015 & 1811 & $16,483.956$ & $<0.001$ \\
\hline Yes & 561 & 572 & & \\
\hline \multicolumn{5}{|l|}{ Breast subtype } \\
\hline HR-/HER2- & 17,493 & 238 & 168.712 & $<0.001$ \\
\hline HR-/HER2+ & 6733 & 167 & & \\
\hline $\mathrm{HR}+/ \mathrm{HER} 2-$ & 99,394 & 1525 & & \\
\hline $\mathrm{HR}+/ \mathrm{HER} 2+$ & 15,956 & 453 & & \\
\hline \multicolumn{5}{|l|}{ ER status } \\
\hline Negative & 25,818 & 432 & 0.212 & 0.645 \\
\hline Positive & 113,758 & 1951 & & \\
\hline \multicolumn{5}{|l|}{ PR status } \\
\hline Negative & 39,323 & 765 & 17.850 & $<0.001$ \\
\hline Positive & 100,253 & 1618 & & \\
\hline \multicolumn{5}{|l|}{ HER2 status } \\
\hline Negative & 116,887 & 1763 & 162.697 & $<0.001$ \\
\hline Positive & 22,689 & 620 & & \\
\hline \multicolumn{5}{|l|}{ Insurance } \\
\hline Uninsured & 2575 & 126 & 148.772 & $<0.001$ \\
\hline Insured & 137,001 & 2257 & & \\
\hline \multicolumn{5}{|l|}{ Marital status } \\
\hline Unmarried & 52,029 & 1101 & 79.707 & $<0.001$ \\
\hline Married & 87,547 & 1282 & & \\
\hline
\end{tabular}

randomized and it was performed in $\mathrm{R}$ software. The best age cutoff values for OS were determined by X-tile software; patients were divided into high, middle, and low groups. We then performed univariate Cox proportional hazards regression analysis to determine the OSrelated variables. Afterward, significant variables in the univariate Cox proportional hazards regression analyses were incorporated into the multivariate Cox proportional hazards regression analyses to determine the independent prognostic factors for IDC patients with BM. Then, a nomogram based on the independent prognostic factors was established to predict the OS for IDC patients with BM. Additionally, time-dependent ROC curves of 1,3 , and 5 years were generated, and the corresponding time-dependent AUCs were used to show the discrimination of the nomogram. Calibration curves and DCA of 1,3 , and 5 years were established. To further validate that the nomogram could perform well in an independent cohort, we validated the nomogram with data from the SEER validation cohort and the AHOCMU cohort. Time-dependent ROC curve, calibration curve, and DCA were also performed in the validation cohort. In the present study, a $P$ value $<0.05$ (two side) was identified as statistical significance.

\section{Results}

Baseline characteristics of the study population

Based on our criteria, a total of 141,959 IDC patients from the SEER database were included, and an additional 113 IDC patients with BM were identified from the AHOCMU for this study. Additionally, 1671 patients were included in the training cohort and 712 patients were included in the validation cohort. As shown in Table 1, 99.24\% of the patients were female and $80.23 \%$ were white. The most common tumor grade of differentiation was grade II (42.01\%). The most common primary site location was in the upperouter quadrant of the breast (39.04\%). There was minimal laterality, with left primary site origins accounting for $50.54 \%$ of the study group and right primary site origins accounting for $49.46 \%$. The most common $\mathrm{T}$ and $\mathrm{N}$ stages were $\mathrm{T} 1$ (63.60\%) and N0 (69.79\%). Regarding the classifications of breast cancer 
Table 4 Multivariate logistic regression analysis of risk factor of bone metastasis in infiltrating duct carcinoma patients

\begin{tabular}{|c|c|c|}
\hline \multirow[t]{2}{*}{ Variables } & \multicolumn{2}{|c|}{ Multivariate logistic regression analysis } \\
\hline & HR $(95 \% \mathrm{Cl})$ & $P$ value \\
\hline \multicolumn{3}{|l|}{ Sex } \\
\hline Female & Reference & \\
\hline Male & $1.507(1.052-2.159)$ & 0.025 \\
\hline \multicolumn{3}{|l|}{ Primary Site } \\
\hline Nipple & Reference & \\
\hline Central portion of breast & $1.169(0.612-2.231)$ & 0.636 \\
\hline Upper-inner quadrant of breast & $1.062(0.555-2.031)$ & 0.856 \\
\hline Lower-inner quadrant of breast & $1.442(0.748-2.783)$ & 0.275 \\
\hline Upper-outer quadrant of breast & $1.084(0.573-2.047)$ & 0.805 \\
\hline Lower-outer quadrant of breast & $1.033(0.538-1.985)$ & 0.922 \\
\hline Axillary tail of breast & $2.024(0.900-4.552)$ & 0.088 \\
\hline Overlapping lesion of breast & $1.178(0.623-2.228)$ & 0.614 \\
\hline \multicolumn{3}{|l|}{ Grade } \\
\hline । & Reference & \\
\hline$\|$ & $1.801(1.498-2.165)$ & $<0.001$ \\
\hline III & $1.266(1.043-1.537)$ & 0.017 \\
\hline IV & $0.422(0.127-1.402)$ & 0.159 \\
\hline \multicolumn{3}{|l|}{ T stage } \\
\hline $\mathrm{T} 1$ & Reference & \\
\hline $\mathrm{T} 2$ & 4.015 (3.499-4.607) & $<0.001$ \\
\hline $\mathrm{T} 3$ & 7.638 (6.417-9.091) & $<0.001$ \\
\hline $\mathrm{T} 4$ & $17.022(14.330-20.218)$ & $<0.001$ \\
\hline \multicolumn{3}{|l|}{$\mathrm{N}$ stage } \\
\hline No & Reference & \\
\hline N1 & $2.709(2.408-3.047)$ & $<0.001$ \\
\hline N2 & $2.570(2.174-3.038)$ & $<0.001$ \\
\hline N3 & 4.651 (3.912-5.529) & $<0.001$ \\
\hline \multicolumn{3}{|l|}{ Brain metastasis } \\
\hline No & Reference & \\
\hline Yes & $14.890(10.102-21.947)$ & $<0.001$ \\
\hline \multicolumn{3}{|l|}{ Liver metastasis } \\
\hline No & Reference & \\
\hline Yes & $19.038(16.042-22.593)$ & $<0.001$ \\
\hline \multicolumn{3}{|l|}{ Lung metastasis } \\
\hline No & Reference & \\
\hline Yes & $13.368(11.400-15.675)$ & $<0.001$ \\
\hline \multicolumn{3}{|l|}{ Breast Subtype } \\
\hline HR-/HER2- & Reference & \\
\hline HR-/HER2+ & $1.201(0.938-1.539)$ & 0.146 \\
\hline $\mathrm{HR}+/ \mathrm{HER} 2-$ & $2.496(2.096-2.972)$ & $<0.001$ \\
\hline HR+/HER2+ & $2.289(1.886-2.778)$ & $<0.001$ \\
\hline
\end{tabular}


Table 4 Multivariate logistic regression analysis of risk factor of bone metastasis in infiltrating duct carcinoma patients (Continued)

\begin{tabular}{|c|c|c|}
\hline \multirow[t]{2}{*}{ Variables } & \multicolumn{2}{|c|}{ Multivariate logistic regression analysis } \\
\hline & HR $(95 \% \mathrm{Cl})$ & $P$ value \\
\hline \multicolumn{3}{|l|}{ Race } \\
\hline Black & Reference & 0.005 \\
\hline Other & $0.811(0.655-1.005)$ & 0.055 \\
\hline White & $1.073(0.928-1.240)$ & 0.341 \\
\hline \multicolumn{3}{|l|}{ Insurance } \\
\hline Uninsured & Reference & \\
\hline Insured & $0.686(0.548-0.859)$ & 0.001 \\
\hline \multicolumn{3}{|l|}{ Marital status } \\
\hline Unmarried & Reference & \\
\hline Married & $0.861(0.782-0.947)$ & 0.002 \\
\hline
\end{tabular}

subtypes, luminal A (HR+/HER2-) accounted for $71.09 \%$. A total of $1133(0.80 \%)$ patients had lung metastases, $202(0.14 \%)$ patients had brain metastasis and $979(0.69 \%)$ patients had liver metastases. Most patients were insured (98.10\%) and married (62.57\%). In our study, most patients were positive for PR (71.76\%) and ER (81.51\%). Regarding therapy, 136,494 $(96.15 \%)$ of the patients underwent surgery, 61,831 $(43.56 \%)$ underwent chemotherapy, and 80,424 (56.65\%) underwent radiotherapy. Table 2 displays information on the clinical and pathological features for the IDC patients with BM.

\section{Risk factors for IDC patients with BM}

As shown in Table 3 , variables with a $P$ value $<0.05$ in the univariate analysis were included in the multivariate logistic regression analysis to determine the risk factors for BM in IDC patients. The results revealed that sex, primary site, grade, $\mathrm{T}$ stage, $\mathrm{N}$ stage, brain metastasis, lung metastasis, liver metastasis,

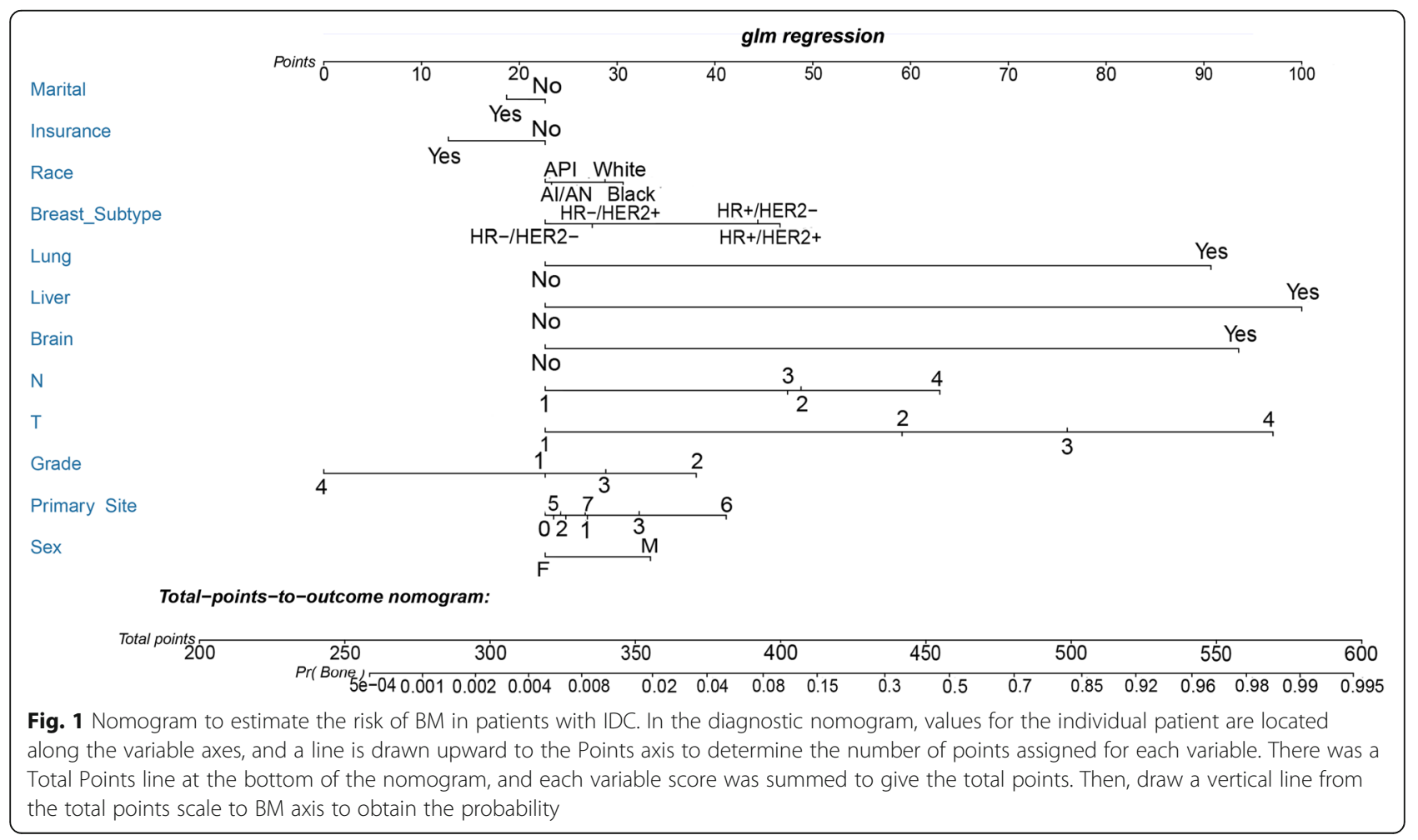


breast cancer subtype, race, insurance status, and marital status were independent predictors for BM in IDC patients (Table 4).

\section{Diagnostic nomogram development and validation}

A nomogram for predicting the risk of BM in IDC patients was established based on the independent predictors (Fig. 1). ROC analysis showed that the AUCs of the nomogram reached 0.907 , demonstrating a better discriminative ability (Fig. 2a). The calibration curve showed high consistency between the observed and predicted results (Fig. 2b). In addition, the DCA indicated that the nomogram had good performance in clinical practice (Fig. 2c).

\section{Prognostic factors for IDC patients with BM}

In the training cohort, the univariate Cox proportional hazards regression analysis showed that age, race, primary site, grade, radiotherapy, surgery, chemotherapy, liver metastasis, lung metastasis, brain metastasis, breast cancer subtype, HER2 status, insurance status, and marital status were prognostic factors (all $P<0.05)$ (Table 5). Then, the multivariate Cox proportional hazards regression analysis was performed. Finally, ten factors, including age, race, grade, surgery, chemotherapy, brain metastases, liver metastases, breast cancer subtypes, insurance status, and marital status, were identified as independent prognostic factors for OS (Table 5).

\section{Prognostic nomogram development and validation}

Based on the prognostic factors selected in the training cohort, a nomogram was established to predict the OS for IDC patients with BM (Fig. 3). ROC analysis showed that the AUCs of these nomograms for the 1-, 3-, and 5year OS reached $0.775,0.758$, and 0.731 in the training cohort; $0.770,0.773$, and 0.753 in the internal validation cohort; and 0.756, 0.764, and 0.767 in the external validation cohort, respectively (Fig. 4a, b, c). The calibration curves of the nomograms showed a strong agreement between actual observations and predictions (Fig. 5). Due to data reasons, the 5-year OS calibration curve for the AHOCMU cohort could not be generated. The clinical application value of the nomogram was evaluated by DCA. As shown in Fig. 6, this nomogram shows a notable positive net benefit over a wide range of death risks, indicating that it has a good clinical utility in predicting the OS for IDC patients with BM. The external validation using the established nomogram in the AHOCMU cohort also demonstrated the high accuracy of the prediction model. Kaplan-Meier survival analysis was performed on the training cohort, internal validation cohort, and external validation cohort, and the results showed that there was an obvious difference in survival rates between the three cohorts (Fig. 7).

\section{Discussion}

Almost all deaths in patients with BC are caused by metastatic disease $[4,5]$. Common metastatic sites include bone, lung, liver, and brain, of which bone is the most common [17, 18]. However, unlike the metastases to the lung, liver and brain, $\mathrm{BM}$ is generally considered to be less fatal [19]. Once $\mathrm{BC}$ patients are diagnosed with $\mathrm{BM}$, the OS decreases dramatically and the median life expectancy decreases to $2-3$ years [20, 21]. IDC is the most common pathological type of $\mathrm{BC}$; therefore, it is necessary to identify the risk and prognostic factors
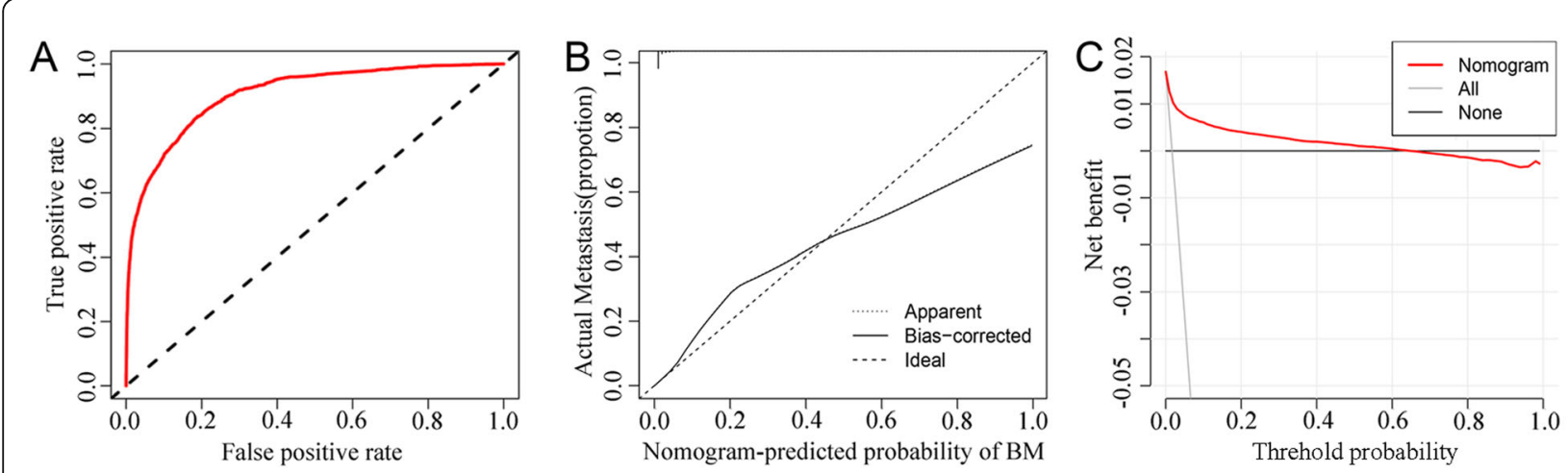

Fig. 2 ROC curves, calibration curves and DCA of the diagnostic nomogram for estimating the risk of BM in patients with IDC. a The area under the ROC curve was used to show the discrimination of the diagnostic nomogram. $\mathbf{b}$ The X-axis represents the nomogram-predicted probability of $\mathrm{BM}$; the $\mathrm{Y}$-axis represents the actual probability of BM. Plots along the 45-degree line indicate a perfect calibration model in which the predicted probabilities are identical to the actual outcomes. c This diagnostic nomogram shows a notable positive net benefit, indicating that it has a good clinical utility in predicting estimating the risk of BM in patients with IDC 
Table 5 Univariate and multivariate Cox proportional hazards regression analysis in infiltrating duct carcinoma patients with bone metastasis

\begin{tabular}{|c|c|c|c|c|}
\hline \multirow[t]{2}{*}{ Characteristics } & \multicolumn{2}{|l|}{ Univariate analysis } & \multicolumn{2}{|l|}{ Multivariate analysis } \\
\hline & HR $(95 \% \mathrm{Cl}) P$ value & & HR $(95 \% \mathrm{Cl}) P$ value & \\
\hline \multicolumn{5}{|l|}{ Race } \\
\hline Black & Reference & & Reference & \\
\hline Other & $0.504(0.359-0.707)$ & $<0.001$ & $0.547(0.387-0.772)$ & 0.001 \\
\hline White & $0.695(0.579-0.834)$ & $<0.001$ & $0.686(0.567-0.831)$ & $<0.001$ \\
\hline \multicolumn{5}{|l|}{ Age } \\
\hline $22-54$ & Reference & & Reference & \\
\hline $55-79$ & $1.511(1.296-1.763)$ & $<0.001$ & $1.523(1.302-1.782)$ & $<0.001$ \\
\hline$\geq 80$ & $2.414(1.942-3.001)$ & $<0.001$ & $2.241(1.768-2.841)$ & $<0.001$ \\
\hline \multicolumn{5}{|l|}{ Sex } \\
\hline Female & Reference & & & \\
\hline Male & $1.236(0.801-1.906)$ & 0.338 & & \\
\hline \multicolumn{5}{|l|}{ Primary Site } \\
\hline Nipple & Reference & & & \\
\hline Central portion of breast & $0.443(0.204-0.961)$ & 0.039 & & \\
\hline Upper-inner quadrant of breast & $0.557(0.258-1.205)$ & 0.138 & & \\
\hline Lower-inner quadrant of breast & $0.619(0.283-1.353)$ & 0.229 & & \\
\hline Upper-outer quadrant of breast & $0.591(0.279-1.251)$ & 0.170 & & \\
\hline Lower-outer quadrant of breast & $0.468(0.214-1.024)$ & 0.057 & & \\
\hline Axillary tail of breast & $0.339(0.099-1.159)$ & 0.085 & & \\
\hline Overlapping lesion of breast & $0.536(0.253-1.139)$ & 0.105 & & \\
\hline \multicolumn{5}{|l|}{ Grade } \\
\hline । & Reference & & Reference & \\
\hline$\|$ & $1.658(1.161-2.368)$ & 0.005 & $1.902(1.329-2.721)$ & $<0.001$ \\
\hline III & $2.436(1.710-3.470)$ & $<0.001$ & $2.819(1.958-4.057)$ & $<0.001$ \\
\hline IV & $4.156(1.274-13.557)$ & 0.018 & $2.527(0.761-8.395)$ & 0.13 \\
\hline \multicolumn{5}{|l|}{ Laterality } \\
\hline Left - origin of primary & Reference & & & \\
\hline Right - origin of primary & $1.022(0.893-1.169)$ & 0.752 & & \\
\hline \multicolumn{5}{|l|}{ T stage } \\
\hline $\mathrm{T} 1$ & Reference & & & \\
\hline $\mathrm{T} 2$ & $0.945(0.765-1.167)$ & 0.600 & & \\
\hline $\mathrm{T} 3$ & $1.252(0.988-1.585)$ & 0.063 & & \\
\hline $\mathrm{T} 4$ & $1.237(0.993-1.541)$ & 0.058 & & \\
\hline \multicolumn{5}{|l|}{ N stage } \\
\hline NO & Reference & & & \\
\hline N1 & $0.944(0.796-1.120)$ & 0.511 & & \\
\hline N2 & $0.916(0.726-1.155)$ & 0.459 & & \\
\hline N3 & $1.087(0.875-1.350)$ & 0.451 & & \\
\hline \multicolumn{5}{|l|}{ Radiotherapy } \\
\hline No & Reference & & & \\
\hline Yes & $0.735(0.628-0.861)$ & $<0.001$ & & \\
\hline Surgery & & & & \\
\hline
\end{tabular}


Table 5 Univariate and multivariate Cox proportional hazards regression analysis in infiltrating duct carcinoma patients with bone metastasis (Continued)

\begin{tabular}{|c|c|c|c|c|}
\hline \multirow[t]{2}{*}{ Characteristics } & \multicolumn{2}{|l|}{ Univariate analysis } & \multicolumn{2}{|l|}{ Multivariate analysis } \\
\hline & HR $(95 \% \mathrm{Cl}) P$ value & & HR $(95 \% \mathrm{Cl}) P$ value & \\
\hline No & Reference & & Reference & \\
\hline Yes & $0.562(0.487-0.648)$ & $<0.001$ & $0.575(0.493-0.669)$ & $<0.001$ \\
\hline \multicolumn{5}{|l|}{ Chemotherapy } \\
\hline No & Reference & & Reference & \\
\hline Yes & $0.769(0.672-0.880)$ & $<0.001$ & $0.730(0.619-0.860)$ & $<0.001$ \\
\hline \multicolumn{5}{|l|}{ Brain metastasis } \\
\hline No & Reference & & Reference & \\
\hline Yes & $2.721(2.132-3.473)$ & $<0.001$ & $2.189(1.699-2.820)$ & $<0.001$ \\
\hline \multicolumn{5}{|l|}{ Liver metastasis } \\
\hline No & Reference & & Reference & \\
\hline Yes & 1.851 (1.584-2.163) & $<0.001$ & $1.744(1.471-2.067)$ & $<0.001$ \\
\hline \multicolumn{5}{|l|}{ Lung metastasis } \\
\hline No & Reference & & & \\
\hline Yes & $1.535(1.325-1.778)$ & $<0.001$ & & \\
\hline \multicolumn{5}{|l|}{ Breast subtype } \\
\hline HR-/HER2- & Reference & & Reference & \\
\hline HR-/HER2+ & $0.263(0.186-0.372)$ & $<0.001$ & $0.281(0.198-0.399)$ & $<0.001$ \\
\hline HR+/HER2- & $0.337(0.278-0.409)$ & $<0.001$ & $0.376(0.299-0.474)$ & $<0.001$ \\
\hline HR+/HER2+ & $0.304(0.238-0.388)$ & $<0.001$ & $0.312(0.242-0.402)$ & $<0.001$ \\
\hline \multicolumn{5}{|l|}{ HER2 status } \\
\hline Positive & Reference & & & \\
\hline Negative & $1.322(1.118-1.563)$ & $=0.001$ & & \\
\hline \multicolumn{5}{|l|}{ Insurance } \\
\hline Uninsured & Reference & & Reference & \\
\hline Insured & $0.684(0.519-0.902)$ & 0.007 & $0.726(0.545-0.966)$ & 0.028 \\
\hline \multicolumn{5}{|l|}{ Marital status } \\
\hline Unmarried & Reference & & Reference & \\
\hline Married & $0.757(0.662-0.866)$ & $<0.001$ & $0.860(0.748-0.989)$ & 0.035 \\
\hline
\end{tabular}

for IDC patients with BM to facilitate the early prevention and detection of $\mathrm{BM}$ and improve the prognosis for IDC patients with BM.

Currently, there are many studies focused on $\mathrm{BM}$ in patients with $\mathrm{BC}$, but there are few studies on IDC patients with BM. Chen et al. reported that in axillary lymph node metastasis, CA125, CA153, ALP, and hemoglobin concentration were independent risk factors for $\mathrm{BM}$ in $\mathrm{BC}$ patients [22]. Yue Gong et al. determined that age, ethnicity, histology, grade, tumor subtype, extra bone metastasis site, and education level were predictors of BM in BC patients [23]. Other studies have also reported that involvement of more than four axillary lymph nodes at initial diagnosis, primary tumor size greater than $2 \mathrm{~cm}$, estrogen receptor positive and progesterone receptor negative tumors and younger age are risk factors for $\mathrm{BM}$ in $\mathrm{BC}$ patients $[24,25]$. This is similar to the results of our study. In our study, sex, primary site, grade, $\mathrm{T}$ stage, $\mathrm{N}$ stage, brain metastasis, lung metastasis, liver metastasis, breast cancer subtype, race, insurance status and marital status were significant predictors for BM in IDC patients. Although Zhao et al. established a nomogram model based on gene expression to predict the risk of $\mathrm{BM}$ in $\mathrm{BC}$ patients, it is not suitable for a wide range of clinical applications and includes all types of $\mathrm{BC}$, which is not conducive to individualized and accurate predictions [26]. To date, no realistic model has been established to 


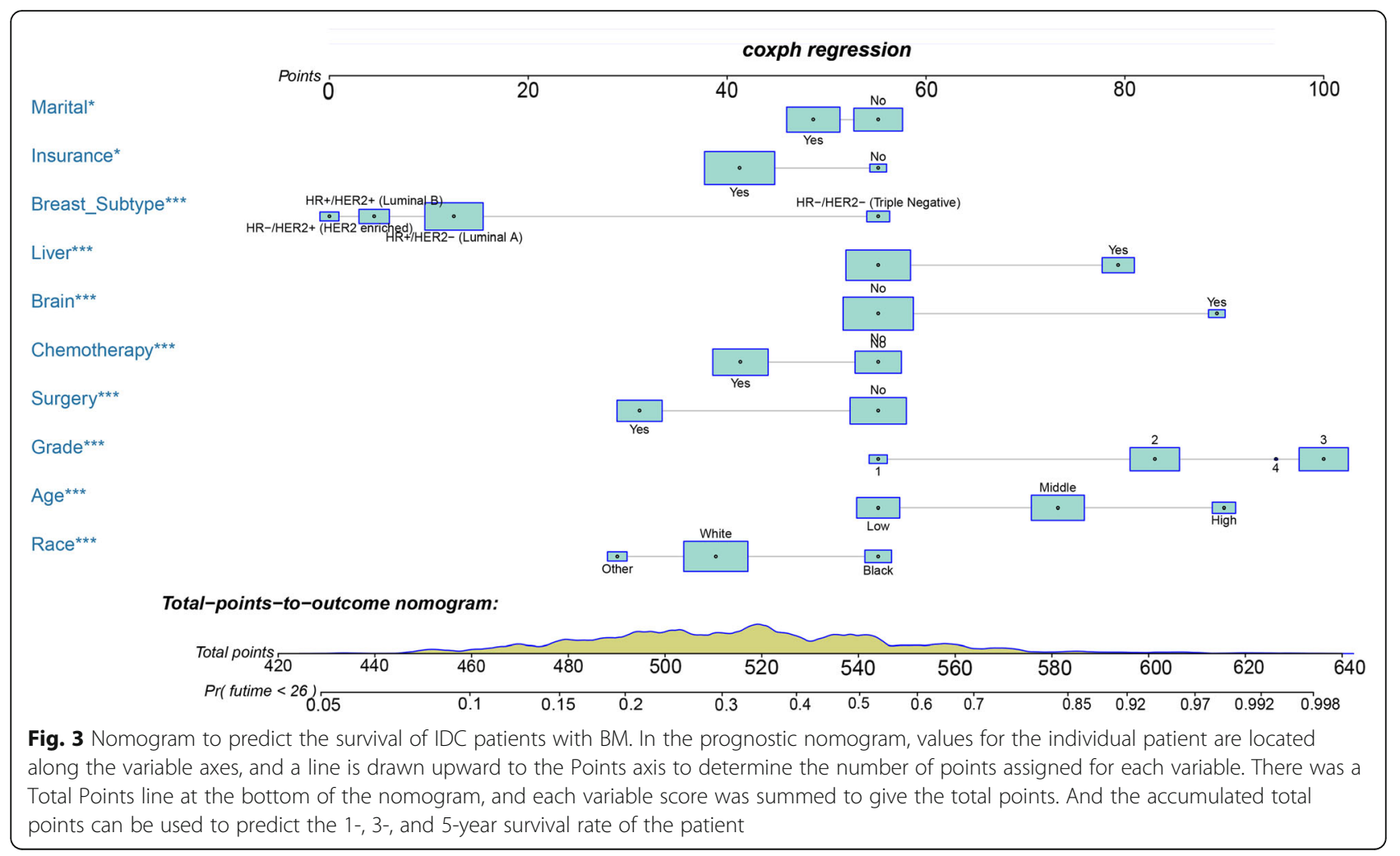

predict the risk and prognosis of BM in ICD patients. To address this problem we extracted, screened, and organized specific and relevant prognostic and risk factors of IDC patients with BM and established an intuitive and practical prediction model. This model is beneficial to both the clinician and the individual patient.
It is generally believed that IDC with only metastases to the bone has a better OS prognosis than IDC with bone and visceral metastasis [27]. Previous studies have also found that patients with BM alone had a median survival of approximately two to three times that of patients with additional visceral metastases [28-30]. Lobbezoo DJ et al. compared the results of
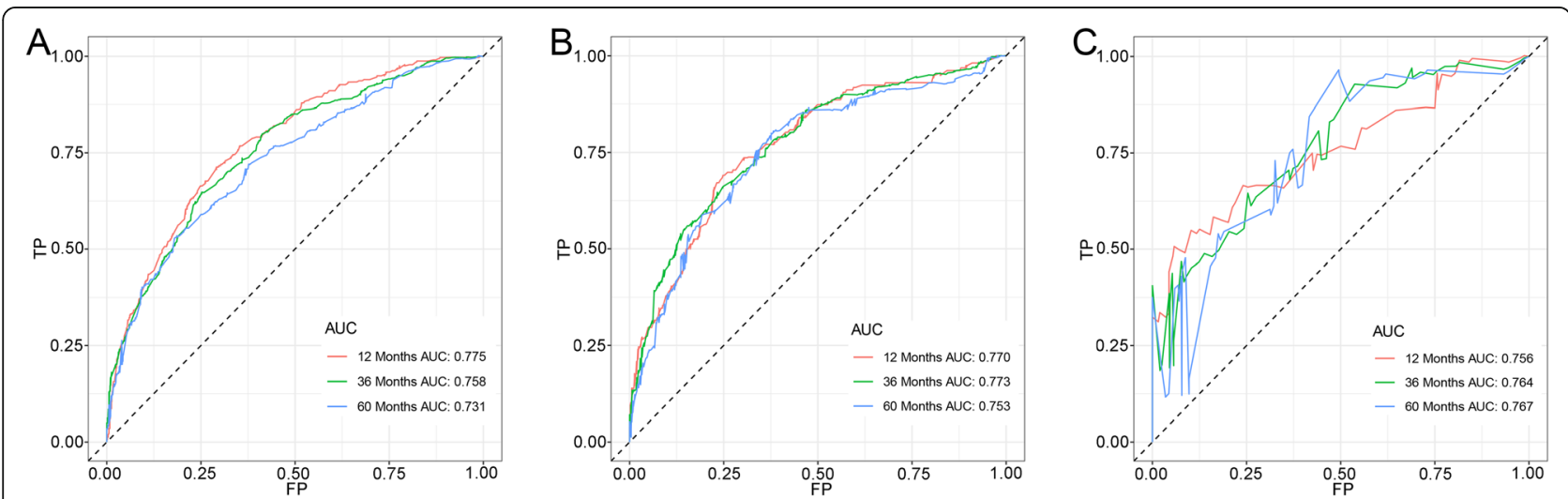

Fig. 4 ROC curves of the nomogram in predicting prognosis at the 1-, 3-, and 5-year points in the training cohort (a), internal validation cohort (b) and external validation cohort (c). The corresponding time-dependent AUCs were used to show the discrimination of the prognostic nomogram. The red line represents the ROC curve for the prognostic nomogram in predicting the prognosis at the 1-year point. The green line represents the ROC curve for the prognostic nomogram in predicting the prognosis at the 3-year point. The blue line represents the ROC curve for the prognostic nomogram in predicting the prognosis at the 5-year point 

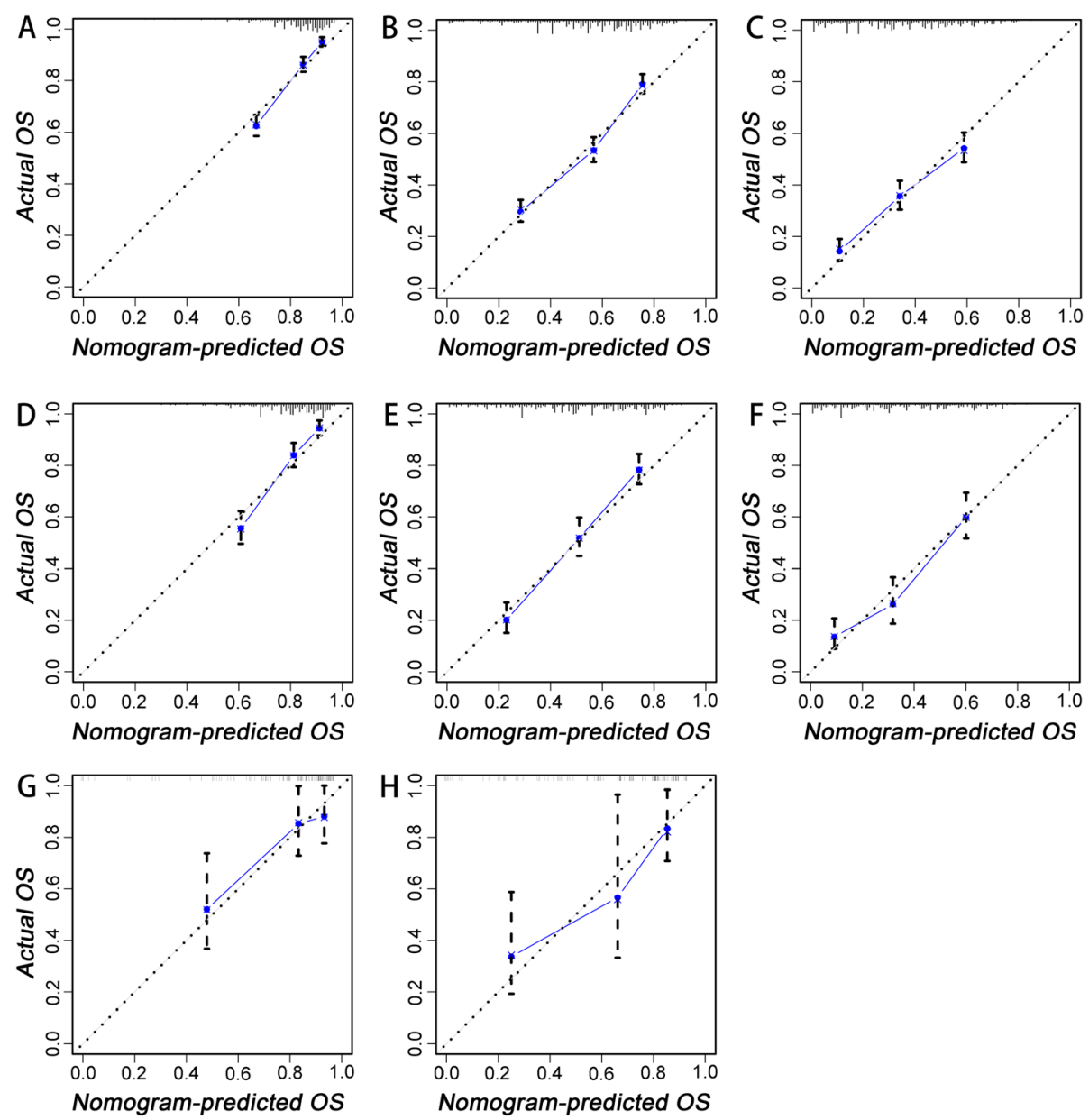

Fig. 5 The calibration curves of the nomogram for the 1-, 3-, and 5-year OS prediction of the training cohort (a-c), internal validation cohort (d-f) and external validation cohort $(\mathbf{g}, \mathbf{h})$. The X-axis represents the nomogram-predicted OS probability; the Y-axis represents the actual OS probability. Plots along the 45 -degree line indicate a perfect calibration model in which the predicted probabilities are identical to the actual outcomes. Vertical bars indicate $95 \%$ confidence intervals

815 patients with primary or recurrent metastatic BC and found that patients with visceral metastases and patients with multiple metastatic sites had a worse prognosis [31]. Interestingly, our results showed that the presence of brain metastasis and liver metastasis had a significant negative impact on the OS, which is consistent with the above results. In addition, we found that the number of metastatic organ sites also had a significant effect on survival. Previous studies have shown that patients with four metastatic sites are 2.2 times more likely to die than patients with only one metastatic site [27]. We speculate that patients with only BM develop vital organ dysfunction later, so these patients have a higher survival rate than those with both bone and extraosseous metastases. According to previous research, the breast cancer subtype is an independent risk factor for the occurrence of metastasis, and the incidence of BM is highest in $\mathrm{BC}$ patients that are $\mathrm{HR}+/ \mathrm{HER} 2-$ or $\mathrm{HR}+$ / HER2+ [23, 32]. Our results show that patients with $\mathrm{HR}+$ /HER2- $\mathrm{BC}$ have a higher risk of BM, and patients with Grade $2 \mathrm{BC}$ are more likely to have $\mathrm{BM}$ compared to patients with Grades 3 and $4 \mathrm{BC}$, which is controversial. At present, most people think that once a tumor has distant organ metastasis, it may accelerate the metastasis to other organs, which is consistent with our results [33]. According to our results, chemotherapy had a positive effect on prognosis. Contrary to what we expected, radiotherapy was not a relevant factor for prognosis. Unfortunately, we were unable to compare the effects of different chemotherapy regimens on survival rates because there was no detailed information on chemotherapy strategies in our data. 


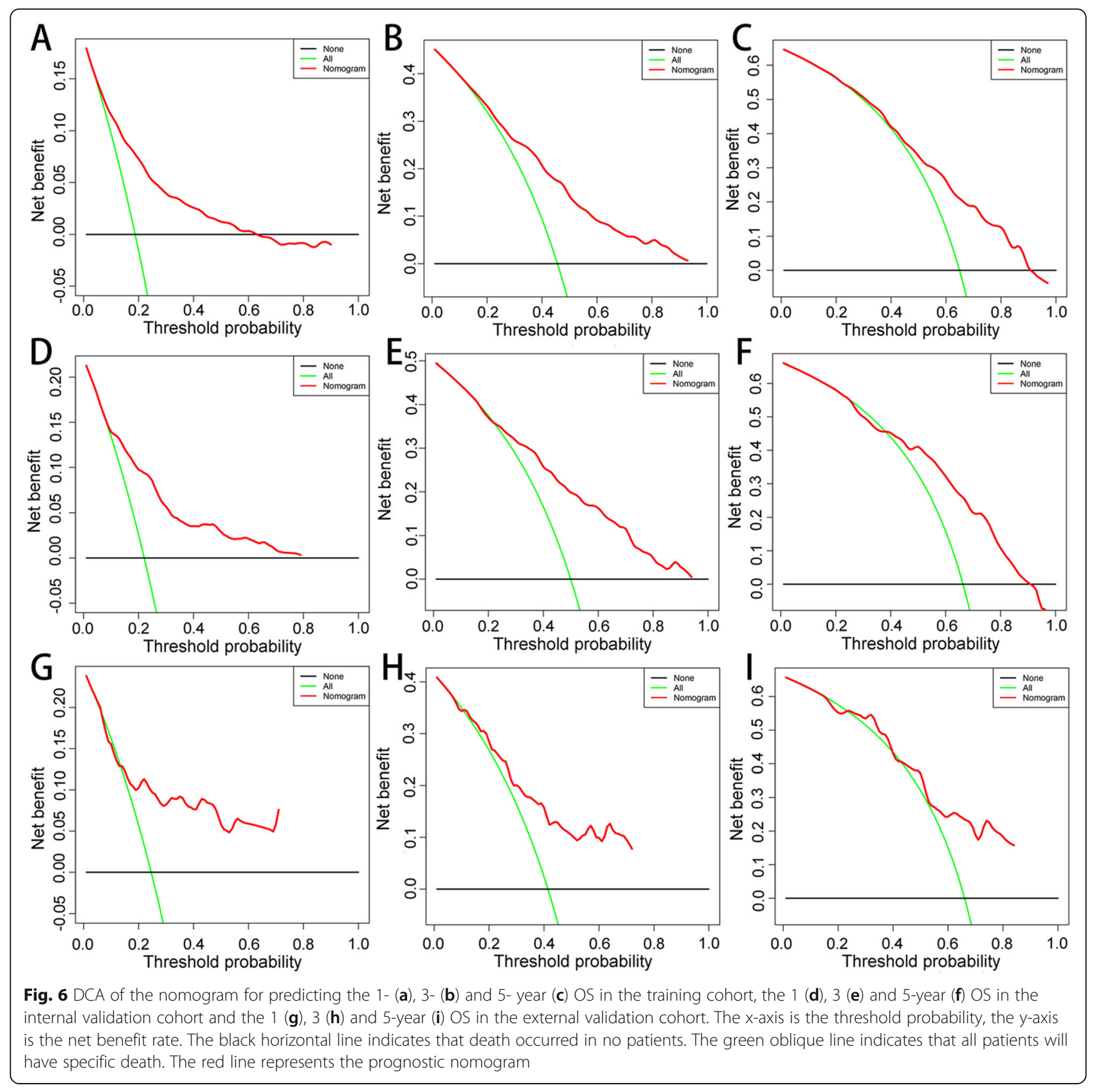

To facilitate clinical work, we established two nomograms to predict the risk and prognosis for $\mathrm{BM}$ in IDC patients. Through calibration, ROC curve and DCA, the nomogram shows great performance, both internally and externally, for predicting the prognosis of IDC patients with BM. These models have better prediction capabilities and higher credibility and can provide references for patient consultations, risk assessment and clinical decision-making. To our knowledge, this is the first population-based model to predict the risk and prognosis of newly diagnosed BM in IDC patients. However, we should acknowledge that this study has some limitations. First, it is a retrospective study and only patients with complete information were included. Therefore, selection bias is likely to exist. Second, some patients with BM have no symptoms, causing the number of newly diagnosed patients with $\mathrm{BM}$ to be lower than the actual number. Third, we did not have specific information about systemic treatments, such as endocrine therapy or HER2 targeted therapy. Fourth, since the data in this study were from the SEER database, the nomogram 


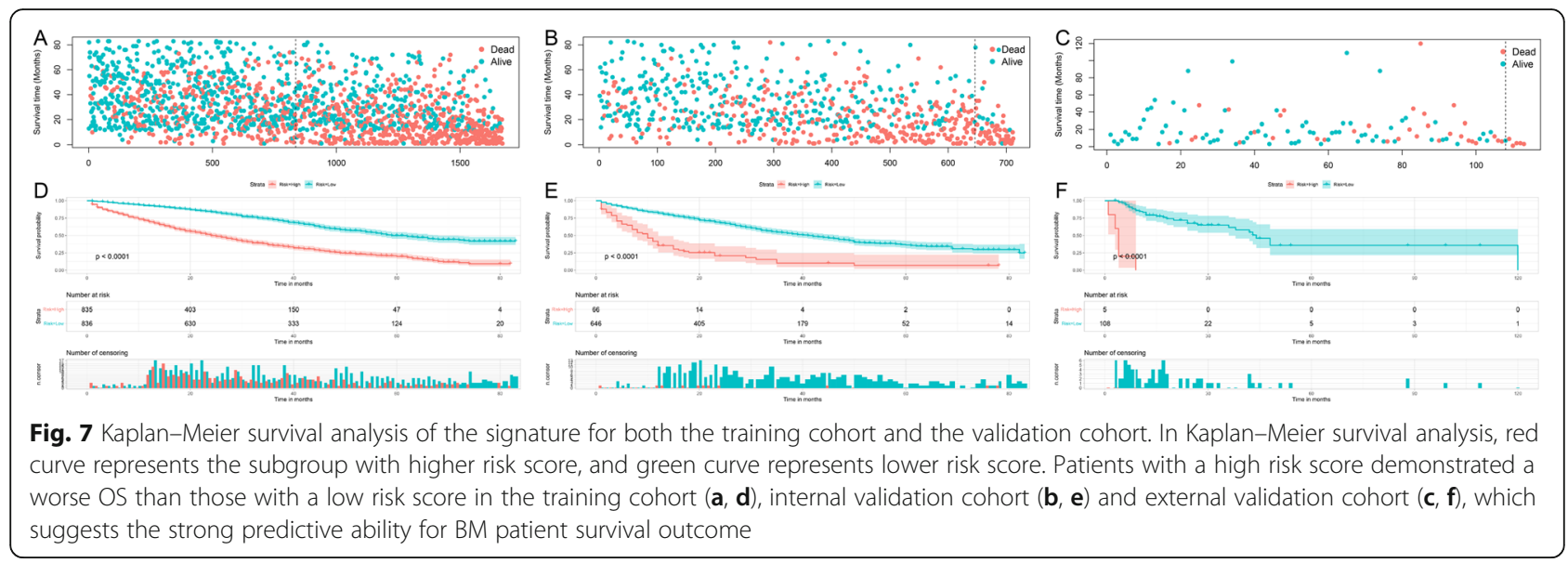

we constructed may not be applicable to IDC patients worldwide.

\section{Conclusion}

These nomograms could be used as a supportive graphic tool in IDC to help clinicians distinguish, assess and evaluate the risk and prognosis of IDC with BM. Internal and external validation and application in an independent population demonstrated the satisfactory performance and clinical utility of this predictive model.

\section{Abbreviations \\ BC: Breast cancer; BM: Bone metastasis; AJCC: American Joint Committee for Cancer; IDC: Infiltrating duct carcinoma; SEER: Surveillance, epidemiology and end results; ER: Estrogen receptor; PR: Progesterone receptor; AHOCMU: Affiliated Hospital of Chengde Medical University; OS: Overall survival; ROC: Receiver operating characteristic; AUC: Area under the curve; DCA: Decision curve analyses}

\section{Acknowledgements}

We would like to thank all the staff in Department of Spine Surgery, Affiliated Hospital of Chengde Medical University for their contribution on our research.

\section{Authors' contributions}

$\mathrm{ZH} \mathrm{H}, \mathrm{CH}, \mathrm{CL} \mathrm{Z}$ and $\mathrm{CC} H$ conceived of and designed the study. ZH H, KW L and $L L Y$ performed literature search. $C H, Y L L$ generated the figures and Tables. $\mathrm{ZH} \mathrm{H}, \mathrm{CH}$ analyzed the data. $\mathrm{ZH} \mathrm{H}$ wrote the manuscript and $\mathrm{CL} \mathrm{Z}$ critically reviewed the manuscript. $\mathrm{ZH} \mathrm{H}, \mathrm{CL} Z$ and $\mathrm{CC} \mathrm{H}$ supervised the research. All authors have read and approved the manuscript.

\section{Funding}

We received no external funding for this study.

\section{Availability of data and materials}

The dataset from SEER database generated and/or analyzed during the current study are available in the SEER dataset repository (https://seer.cancer. gov/).

\section{Ethics approval and consent to participate}

We received permission to access the research data file in the SEER program from the National Cancer Institute, US (reference number 15260-Nov2018). Approval was waived by the local ethics committee, as SEER data is publicly available and de-identified.
Consent for publication

Not applicable.

\section{Competing interests}

The authors declare that they have no competing interests.

\section{Author details}

'Department of Spine Surgery, Affiliated Hospital of Chengde Medical University, No.36 Nanyingzi St, Shuangqiao District, Chengde, Hebei Province, China. ${ }^{2}$ Department of Orthopedic, The Affiliated Hospital of Qingdao University, Shinan District, Qingdao, Shandong Province, China. ${ }^{3}$ Department of Oncology, Affiliated Hospital of Chengde Medical University, No.36 Nanyingzi St, Shuangqiao District, Chengde, Hebei Province, China.

Received: 12 March 2020 Accepted: 13 November 2020

Published online: 25 November 2020

\section{References}

1. Siegel RL, Miller KD, Jemal A. Cancer statistics, 2018. CA Cancer J Clin. 2018; 68(1):7-30.

2. Fitzmaurice C, Akinyemiju TF, Al Lami FH, Alam T, Alizadeh-Navaei R, Allen C, Alsharif A-GN, Amini E, Anderson BO, et al. Global, regional, and National Cancer Incidence, mortality, years of life lost, years lived with disability, and disability-adjusted life-years for 29 Cancer groups, 1990 to 2016: a systematic analysis for the global burden of disease study. JAMA Oncol. 2018;4(11):1553-68.

3. Bray F, Ferlay J, Soerjomataram I, Siegel RL, Torre LA, Jemal A. Global cancer statistics 2018: GLOBOCAN estimates of incidence and mortality worldwide for 36 cancers in 185 countries. CA Cancer J Clin. 2018;68(6):394-424.

4. DeSantis CE, Fedewa SA, Goding Sauer A, Kramer JL, Smith RA, Jemal A. Breast cancer statistics, 2015: convergence of incidence rates between black and white women. CA Cancer J Clin. 2016:66(1):31-42.

5. Li Z, Kang Y. Emerging therapeutic targets in metastatic progression: a focus on breast cancer. Pharmacol Ther. 2016;161:79-96.

6. Yerushalmi R, Tyldesley S, Kennecke H, Speers C, Woods R, Knight B, Gelmon KA. Tumor markers in metastatic breast cancer subtypes: frequency of elevation and correlation with outcome. Ann Oncol. 2012;23(2):338-45.

7. Kennecke $\mathrm{H}$, Yerushalmi R, Woods R, Cheang MC, Voduc D, Speers CH, Nielsen TO, Gelmon K. Metastatic behavior of breast cancer subtypes. J Clin Oncol Off J Am Soc Clin Oncol. 2010;28(20):3271-7.

8. Suva LJ, Washam C, Nicholas RW, Griffin RJ. Bone metastasis: mechanisms and therapeutic opportunities. Nat Rev Endocrinol. 2011;7(4):208-18.

9. McDonald ES, Clark AS, Tchou J, Zhang P, Freedman GM. Clinical diagnosis and Management of Breast Cancer. J Nuclear Med. 2016;57:9S-16S.

10. Lipton A. Should bisphosphonates be utilized in the adjuvant setting for breast cancer? Breast Cancer Res Treat. 2010;122(3):627-36.

11. Burke HB. Outcome prediction and the future of the TNM staging system. J Natl Cancer Inst. 2004;96(19):1408-9. 
12. Park YH, Lee SJ, Cho EY, La Choi Y, Lee JE, Nam SJ, Yang JH, Shin JH, Ko EY, Han BK, et al. Clinical relevance of TNM staging system according to breast cancer subtypes. Ann Oncol. 2019;30(12):2011.

13. Balachandran VP, Gonen M, Smith JJ, DeMatteo RP. Nomograms in oncology: more than meets the eye. Lancet Oncol. 2015;16(4):e173-80.

14. Molland JG, Donnellan M, Janu NC, Carmalt HL, Kennedy CW, Gillett DJ. Infiltrating lobular carcinoma--a comparison of diagnosis, management and outcome with infiltrating duct carcinoma. Breast. 2004;13(5):389-96.

15. Liu RZ, Zhao ZR, Ng CS. Statistical modelling for thoracic surgery using a nomogram based on logistic regression. J Thorac Dis. 2016;8(8):E731-6.

16. Vickers AJ, Elkin EB. Decision curve analysis: a novel method for evaluating prediction models. Med Decis Mak. 2006;26(6):565-74.

17. Parkin DM, Pisani P, Ferlay J. Estimates of the worldwide incidence of 25 major cancers in 1990. Int J Cancer. 1999;80(6):827-41.

18. Wu Q, Li J, Zhu S, Wu J, Chen C, Liu Q, Wei W, Zhang Y, Sun S. Breast cancer subtypes predict the preferential site of distant metastases: a SEER based study. Oncotarget. 2017;8(17):27990-6.

19. Abdel-Rahman O. Population-based validation of the National Cancer Comprehensive Network recommendations for breast cancer staging. Breast Cancer Res Treat. 2018;172(1):231-8.

20. Li S, Peng Y, Weinhandl ED, Blaes AH, Cetin K, Chia VM, Stryker S, Pinzone JJ, Acquavella JF, Arneson TJ. Estimated number of prevalent cases of metastatic bone disease in the US adult population. Clin Epidemiol. 2012;4: 87-93.

21. Zhang H, Zhu W, Biskup E, Yang W, Yang Z, Wang H, Qiu X, Zhang C, Hu G, $\mathrm{Hu}$ G. Incidence, risk factors and prognostic characteristics of bone metastases and skeletal-related events (SRES) in breast cancer patients: a systematic review of the real world data. J Bone Oncol. 2018;11:38-50.

22. Chen WZ, Shen JF, Zhou Y, Chen XY, Liu JM, Liu ZL. Clinical characteristics and risk factors for developing bone metastases in patients with breast cancer. Sci Rep. 2017;7(1):11325.

23. Gong Y, Zhang J, Ji P, Ling H, Hu X, Shao ZM. Incidence proportions and prognosis of breast cancer patients with bone metastases at initial diagnosis. Cancer Med. 2018;7(8):4156-69.

24. Colleoni M, O'Neill A, Goldhirsch A, Gelber RD, Bonetti M, Thürlimann B, Price KN, Castiglione-Gertsch M, Coates AS. Lindtner jet al: identifying breast cancer patients at high risk for bone metastases. J Clin Oncol. 2000;18(23): 3925-35.

25. Wei B, Wang J, Bourne P, Yang Q, Hicks D, Bu H, Tang P. Bone metastasis is strongly associated with estrogen receptor-positive/progesterone receptornegative breast carcinomas. Hum Pathol. 2008;39(12):1809-15.

26. Zhao C, Lou Y, Wang Y, Wang D, Tang L, Gao X, Zhang K, Xu W, Liu T, Xiao $J$. A gene expression signature-based nomogram model in prediction of breast cancer bone metastases. Cancer Med. 2019;8(1):200-8.

27. Leone BA, Vallejo CT, Romero AO, Machiavelli MR, Pérez JE, Leone J, Leone JP. Prognostic impact of metastatic pattern in stage IV breast cancer at initial diagnosis. Breast Cancer Res Treat. 2017;161(3):537-48.

28. Harries M, Taylor A, Holmberg L, Agbaje O, Garmo H, Kabilan S, Purushotham A. Incidence of bone metastases and survival after a diagnosis of bone metastases in breast cancer patients. Cancer Epidemiol. 2014;38(4): 427-34.

29. Jacobson AF, Shapiro CL, Van den Abbeele AD, Kaplan WD. Prognostic significance of the number of bone scan abnormalities at the time of initial bone metastatic recurrence in breast carcinoma. Cancer. 2001;91(1):17-24.

30. Plunkett TA, Smith P, Rubens RD. Risk of complications from bone metastases in breast cancer. implications for management. Eur J Cancer. 2000;36(4):476-82

31. Lobbezoo DJ, van Kampen RJ, Voogd AC, Dercksen MW, van den Berkmortel F, Smilde TJ, van de Wouw AJ, Peters FP, van Riel JM, Peters NA, et al. Prognosis of metastatic breast cancer: are there differences between patients with de novo and recurrent metastatic breast cancer? $\mathrm{Br} J$ Cancer. 2015;112(9):1445-51.

32. Metzger-Filho O, Sun Z, Viale G, Price KN, Crivellari D, Snyder RD, Gelber RD, Castiglione-Gertsch M, Coates AS, Goldhirsch A, et al. Patterns of recurrence and outcome according to breast cancer subtypes in lymph node-negative disease: results from international breast cancer study group trials VIII and IX. J Clin Oncol. 2013;31(25):3083-90.

33. Xie J, Ying $Y Y, X u B$, Li Y, Zhang X, Li C. Metastasis pattern and prognosis of male breast cancer patients in US: a population-based study from SEER database. Ther Adv Med Oncol. 2019:11:1758835919889003.

\section{Publisher's Note}

Springer Nature remains neutral with regard to jurisdictional claims in published maps and institutional affiliations.

\section{Ready to submit your research? Choose BMC and benefit from:}

- fast, convenient online submission

- thorough peer review by experienced researchers in your field

- rapid publication on acceptance

- support for research data, including large and complex data types

- gold Open Access which fosters wider collaboration and increased citations

- maximum visibility for your research: over $100 \mathrm{M}$ website views per year

At BMC, research is always in progress.

Learn more biomedcentral.com/submissions 